\title{
American Pediatric Society's 2016 John Howland Award acceptance lecture: every newborn matters-progress and promise
}

\author{
Barbara J. Stoll ${ }^{1}$
}

Colleagues and friends,

A heartfelt thank you to those who nominated me and to Peggy Hostetter and the Council of the American Pediatric Society for selecting me to receive the Howland award. This is an extraordinary honor-a special moment to savor and to treasure.

Thanks to Lucky Jain for a lovely introduction. More importantly, thanks Lucky for many years of close partnership and friendship in the Department of Pediatrics at Emory. A special thank you and appreciation to the many people I have worked with over the years-mentors, including Drs. Michael Katz, Andre Nahmias, and Al Brann; collaborators in the neonatal and obstetrical communities in the United States, including my co-investigators in the NICHD Neonatal Research and Stillbirth Collaborative Research Networks; colleagues in the global maternal and child health community; and of course my friends and colleagues at Emory and now McGovern Medical School at UTHealth. You have been my work family and have made it a joy to come to work every day. Thanks also to the many families over the years who have put their trust in me as a physician and as an investigator.

Those who work behind the scenes at American Pediatric Society know that Brenda Peat is the quiet force who gets so much accomplished, making other people look good because of her graciousness, hard work, and attention to detail. Brenda, thank you so much.

Finally, a very special thank you to my family. I had the good fortune to have wonderful parents for whom education and making a contribution to the broader world were important values. Thanks to my sister who has always been a source of support. My husband, Roger Glass, has been my partner in crime since I was $19 \mathrm{y}$ old. With his love and unwavering support, he has pushed me to do things that I would never have even considered. We have had an extraordinary and unusual life together. Who you choose as a life partner matters-and I am grateful to have chosen very well.
Thanks to our children, Nina, Michael and Andy Glass for teaching me what is really important in life. You are not only people whom I love, but people whom I respect and admire for your kindness, your choices, and your paths in life.

John Howland was a remarkable man who made important contributions to the pediatrics of his time (1). I am proud to share New York City and Columbia Presbyterian roots with Dr. Howland. Perhaps Dr. Howland's greatest contribution to pediatrics was in building a department at Johns Hopkins where all faculty members were full-time academics-the model for today's academic department, with a focus on research. It has been written that he surrounded himself with remarkable and brilliant young MEN-people whose names we rememberKenneth Blackfan, Edwards Parks, Grover Powers, James Gamble, to name a few. Born in 1873, Howland graduated from medical school in 1897 and was active in pediatrics through the early 1900s-a time when few women entered the field of medicine and even fewer held leadership roles.

It is especially meaningful to me to be among only 10 women to have received the Howland Award since it first began in 1952. That said, it is noteworthy that the last 4 Howland awardees have been women. With pride and hope, I have often quoted the Chinese saying, "Women hold up half the sky." I am grateful for the opportunities I have been given but also mindful of the importance of seizing and embracing opportunities-for all of us, but especially for women.

I have had a wonderful career. It continues to be challenging and meaningful, and fun. I have been surrounded by extraordinary people - women and men-master clinicians, child advocates, great teachers, great scientists, and great leaders-people who are committed to making a difference in the lives of others. Medicine is a remarkable profession. We are privileged to be physicians, allowed into the lives of patients and families at their most vulnerable. An academic career allows us to be students and to be teachers-asking and answering important questions throughout our careers. 


\section{Special Article}

This morning I want to reflect briefly on changes in neonatology, health disparities, and maternal and neonatal health from a global perspective.

To start, a patient story:

It is August 1963. A 34-y-old Caucasian woman arrives at Otis Air Force Base on Cape Cod, Massachusetts in active labor. Her previous pregnancies resulted in two healthy children and two pregnancy losses. Born by cesarean section, the baby boy is premature arriving $5.5 \mathrm{wk}$ early and weighing 4 pounds, 10.5 ounces. Soon after birth, he develops respiratory distress syndrome, the most common cause of death of premature infants at the time. According to a status report from the NIH, about 25,000 babies were thought to succumb to respiratory distress syndrome that year alone. The infant is transferred to Boston Children's Hospital. His parents have access to the best care money can buy, but even the best hospitals do not have modern neonatal intensive care units in 1963. Respiratory support-continuous positive airway pressure and ventilators are not being used on such tiny patients. A leading pediatrician is dispatched to the scene from New York City. The baby, Patrick Bouvier Kennedy, dies just $39 \mathrm{~h}$ after his birth (2).

Patrick Kennedy was the first baby born to a sitting president and first lady since the 19th century. His death was a personal and very public tragedy that science has largely overcome. Many have noted that Patrick Kennedy's death sparked an intense interest in neonatology and infant mortality with extraordinary progress in the 50 plus years since his birth. Perhaps most remarkable, what is common place today was unheard of back then. Imagine if Patrick, or any one of the 25,000 babies who died in the United States that year from respiratory distress syndrome, had been born today?

The last few decades have been a golden age for maternal fetal medicine and neonatology in the United States, with increasing collaboration between the disciplines, an expanded evidence base, changes in care practices and most importantly, improved outcomes. Antenatal corticosteroids, intrapartum antibiotics, neonatal resuscitation, thermoregulation, surfactant, continuous positive airway pressure, ventilation strategies, noninvasive monitoring, ultrasound and advanced imaging, central venous catheters and parenteral nutrition, extra corporeal membrane oxygenation, care bundles to reduce risk of infection, developmentally supportive care-the numerous technologies and strategies that are routine today, are scientific victories for our tiniest patients and their families.

Of note, the Cochrane Collaboration (3), which has helped transform the way healthcare decisions are made, by systematically evaluating evidence on benefits and hazards of important therapies, began in the field of neonatal-perinatal medicine with the Oxford Database of Perinatal Trials (4) and was later expanded to other areas of healthcare. Cochrane systematic reviews led to the practice of evidence-based medicine and set the stage for today's learning healthcare systems. The word collaboration is important. The power of collaboration to push the boundaries of science and medicine and clinical care cannot be overemphasized.
In 1963, it was unimaginable that the care of a baby born at $\sim 34$ wk gestation would be considered routine. Today, the "cutting edge" of neonatology involves care for the tiniest of babies provided intensive care. Extremely preterm infants, defined by the World Health Organization as infants born before $28 \mathrm{wk}$ gestational age, constitute a small proportion of births worldwide, but the majority of neonatal deaths and of infants with short and long-term neonatal morbidities.

Accurate information on the most up to date evidence-based care and outcomes of these tiny infants is essential to help physicians and families make informed decisions and consider likely outcomes. Research has driven new therapies and care paradigms have changed, with greater adherence to maternal and neonatal interventions and guidelines known to improve outcomes. For example, despite compelling evidence that antenatal corticosteroids to enhance fetal lung maturity decreased respiratory distress syndrome, intraventricular hemorrhage, and mortality (5), as recently as the early 1990s, less than a quarter of those delivering extremely premature infants in the United States received antenatal steroids. Today, the vast majority of mothers delivering extremely preterm infants receive this therapy.

Recent work from the NICHD Neonatal Research Network (6), the Vermont Oxford Network (7), as well as investigations from Canada, several European countries, Israel, Japan, Australia, and New Zealand have demonstrated a significant increase in survival to hospital discharge for the tiniest infants. Perhaps the most important and most optimistic finding from a recent NIH Neonatal Network study is a significant increase in survival to hospital discharge without major in-hospital neonatal morbidities; these include infection, intracranial hemorrhage, periventricular leukomalacia, and retinopathy of prematurity (6). Although we are optimistic that these improvements in shortterm outcomes will translate into improved long-term outcomes, it is critical to develop specific neuro-protective and neuro-promoting "brain care bundles" similar to successful approaches to reduce infections. A focus on the brain and long-term outcomes is the future of neonatal care. Innovative technologies and new funding streams in neuroscience, including the NIH BRAIN Initiative launched by NIH Director, Dr. Francis Collins and President Obama, must include the fetus and newborn.

Optimism, however, always needs to be tempered by caution. The history of neonatology is a cautionary tale of great successes but also tragic medical errors-not all avoidable. The late Dr. William Silverman noted that we cannot always make children better, but we can always make them worse. One of the fathers of modern neonatology, Dr. Silverman witnessed a series of disasters in the early days of neonatology and "was disturbed by how long it took to recognize the harmful effects of specific treatments." He became a passionate advocate for "increased use of the randomized controlled clinical trial to find out if treatments were beneficial and discover any unexpected risks." He also made us consider the distinction between "knowing" and "doing" and implored neonatologists-really society at large-to think beyond survival to understand longterm outcomes and consider quality of life (8). 
My colleague at The University of Texas, Dr. Jon Tyson, has written about the "ethics of evidence." He and others have stressed the importance of well-designed clinical studies and careful evaluation of the evidence to drive best practices and effective and ethical care (9). I have come to use the term "the science of clinical care." Outstanding clinical care is no longer an art, but the confluence of evidence and experience-and I might add-of genuine concern for patients and families. The human dimension of patients and families is at the forefront of caring for the tiniest of babies-but always needs to be bolstered by science and evidence.

Research must drive and inform clinical care. Collaborations between bench researchers and clinician scientists are more important than ever. Fundamental science is the basis for new clinical interventions. We have many examples from infectious diseases care and research. For example, understanding basic mechanisms of infectious agents led to the development of vaccines and now our children are immunized against common childhood illnesses that were once major causes of death and disability. Not so long ago, transmission of HIV from an infected mother to her newborn was common and a virtual death sentence for mother and baby. Today, elimination of maternal to child transmission of HIV is a near reality, and AIDS itself has become a manageable chronic disease with the hopes that new drug strategies will usher in an end to the AIDS era.

To the young physicians and scientists here today, including my own daughter, you live in a wonderful and exciting era for science and medicine. The promise of precision medicine will be reached in your lifetimes. There will be successful new stem cell therapies, CRISPR and gene editing, targeted new drugs and vaccines and devices to ward off today's most threatening illnesses. It is hard to imagine what science and creative minds and unique collaborative partnerships will bring us tomorrow.

Now it is your opportunity to build on recent advances and to tackle the most complex and pressing medical challenges that cross boundaries of specialties and disciplines. Dare to discover and push the envelope of science and medicine. Remember that neonatal ventilation and high-tech neonatal ICUs were as improbable and cutting-edge in 1963 as precision medicine and gene based therapies are today. Be missionaries and advocates for science and medicine-always mindful of the best interests of children and the ethical dimension of what you do.

Although survival of extremely preterm infants in the United States has increased over the past several decades, including survival without major morbidities, the individual and societal burden of preterm birth remains substantial, with approximately 450,000 neonates born prematurely in the United States each year (10). The medical and public health communities must do better at ensuring that known interventions to reduce risk of prematurity are followed. At the same time, innovative strategies to address the problem of preterm birth remain a pressing need. Moreover, racial and ethnic disparities in preterm birth, with unacceptable racial disparities in neonatal and infant mortality rates, need urgent attention. It has been noted that zip code is one of the greatest risk factors for preterm birth and neonatal mortality in the United States. The American Academy of Pediatrics' recent policy statement on poverty and child health underscores the impact of poverty and social determinants of health (11).

Mother's day is a week from today. Mothers throughout the world-from rich countries and poor-have the same hopes of delivering a healthy baby, with a healthy start in life. The writer and psychologist Alison Gopnik, writing about her own grandchild, reminds us that having a child with an illness "makes you especially aware of how infinitely vulnerable and infinitely valuable all children are (12)." A core principle of pediatrics and pediatric research and advocacy, must be the fundamental value of all children and the importance to each one of us of health as a human right.

Although the last few decades have seen extraordinary advances in maternal and neonatal care and outcomes in the United States and other high income countries, these advances have not translated into uniformly improved care and outcomes for mothers and newborns throughout the world. The first few days of life remain the most dangerous for newborns. According to the recent Millennium Development Goals Report, the rate of neonatal mortality worldwide fell from 33 to 19 deaths per 1,000 live births between 1990 and 2015-certainly very good news (13). But, that still equates to $\sim 1$ million newborns who die on the first day of life, an additional 1 million who die in the first week, and $\sim 2.8$ million who die during the neonatal period. Almost half of the $\sim 6$ million under 5 deaths each year occur among newborns (14). The greatest burden of neonatal mortality is in low and middle income countries, with three-quarters of all neonatal deaths occurring in Southern Asia and sub-Saharan Africa. Worldwide, children from poorer families, children from rural versus urban areas, children whose mothers are not educated, are more likely to die in the neonatal period.

The majority of these deaths are caused by complications of preterm birth; complications during labor and delivery, including asphyxia; and infections. A focus on newborns is critical to advancing progress in overall child mortality and well-being. In addition to these neonatal deaths, $\sim 2.6$ million stillbirths occur each year, 98 percent in low and middle income countries-an enormous global burden.

Most troubling, from a human perspective, is that many of these stillbirths and neonatal deaths could be prevented with access to quality healthcare and simple low-cost interventions that address the needs of mothers and babies, particularly during labor and delivery and the first few days of life. Nearly one in four babies worldwide are still delivered without a skilled birth attendant - a doctor, nurse or midwife. Skilled attendance at birth and institutional deliveries are lowest in countries with the highest rates of stillbirth and neonatal mortality. Enhanced access to skilled care during childbirth, including emergency obstetric care if needed, coupled with community based postpartum care and hospital referral, are cost effective interventions that save lives. Newborn survival is inextricably tied to maternal health, underscoring the link between newborn health and the broader context of reproductive and maternal health. 


\section{Special Article}

We have a human rights imperative to give every mother and newborn a voice and to make every newborn matter. I like to think of myself as an "impatient optimist," a term coined by Bill and Melinda Gates (15). Increased awareness of the magnitude of the problem coupled with influential international partnerships are reasons for optimism. The confluence of political will and commitment, global financial resources, and country level programs brought to scale are essential to leveling the playing field so that all babies-rich and poor-have a healthy and fair start in life. Let's work to make Mother's Day a joyous day for mothers and families throughout the world. Thank you. Thanks again for this extraordinary honor, and please remember your mother next Sunday!

\section{REFERENCES}

1. Chesney RW. Who was John Howland and why was an award named after him 50 years ago? Pediatr Res 2003;53:523-5.

2. Altman L. A Kennedy baby's life and death. The New York Times, 29 July 2013. (http://www.nytimes.com/2013/07/30/health/a-kennedy-babys-lifeand-death.html?_r=0).

3. Chalmers I. The Cochrane collaboration: preparing, maintaining, and disseminating systematic reviews of the effects of health care. Ann N Y Acad Sci 1993;703:156-63; discussion 163-5.

4. Chalmers I, Hetherington J, Newdick M, et al. The Oxford Database of Perinatal Trials: developing a register of published reports of controlled trials. Control Clin Trials 1986;7:306-24.
5. National Institutes of Health. The effect of antenatal steroids for fetal maturation on perinatal outcomes. NIH Consensus Statement, 1994; 12:1-24.

6. Stoll BJ, Hansen NI, Bell EF, et al.; Eunice Kennedy Shriver National Institute of Child Health and Human Development Neonatal Research Network. Trends in care practices, morbidity, and mortality of extremely preterm neonates, 1993-2012. JAMA 2015;314:1039-51.

7. Horbar JD, Carpenter JH, Badger GJ, et al. Mortality and neonatal morbidity among infants 501 to 1500 grams from 2000 to 2009. Pediatrics 2012;129:1019-26.

8. Gartner LM, William A. Silverman - oral history project. American Academy of Pediatrics: Pediatric History Center, 1997.

9. Tyson JE, Stoll BJ. Evidence-based ethics and the care and outcome of extremely premature infants. Clin Perinatol 2003;30:363-87.

10. McCabe ER, Carrino GE, Russell RB, Howse JL. Fighting for the next generation: US Prematurity in 2030. Pediatrics 2014;134: 1193-9.

11. Council on Community Pediatrics. Poverty and child health in the United States. Pediatr, 2016; 137:1-14

12. Gopnik A. Giving thanks for the innovation that saves babies. The Wall Street Journal. 25 November 2015. (http://www.wsj.com/articles/givingthanks-for-the-innovation-that-saves-babies-1448391887).

13. United Nations, The millennium development goals report 2015, 2015. (http://www.un.org/millenniumgoals/reports.shtml).

14. Lawn JE, Blencowe H, Oza S, et al.; Lancet Every Newborn Study Group. Every Newborn: progress, priorities, and potential beyond survival. Lancet 2014;384:189-205.

15. Impatient Optimists. About Us, 2016. (http://www.impatientoptimists.org/ About-This-Site). 